\title{
Transitions in mechanical behavior and in deformation mechanisms enhance the strength and ductility of $\mathrm{Mg}-\mathbf{3 G d}$
}

Luo, Xuan; Feng, Zongqiang; Yu, Tianbo; Luo, Junqian; Huang, Tianlin; Wu, Guilin; Hansen, Niels; Huang, Xiaoxu

Published in:

Acta Materialia

Link to article, DOI:

10.1016/j.actamat.2019.11.034

Publication date:

2020

Document Version

Peer reviewed version

Link back to DTU Orbit

Citation $(A P A)$ :

Luo, X., Feng, Z., Yu, T., Luo, J., Huang, T., Wu, G., Hansen, N., \& Huang, X. (2020). Transitions in mechanical behavior and in deformation mechanisms enhance the strength and ductility of Mg-3Gd. Acta Materialia, 183, 398-407. https://doi.org/10.1016/j.actamat.2019.11.034

\section{General rights}

Copyright and moral rights for the publications made accessible in the public portal are retained by the authors and/or other copyright owners and it is a condition of accessing publications that users recognise and abide by the legal requirements associated with these rights.

- Users may download and print one copy of any publication from the public portal for the purpose of private study or research.

- You may not further distribute the material or use it for any profit-making activity or commercial gain

- You may freely distribute the URL identifying the publication in the public portal 


\title{
Transitions in mechanical behavior and in deformation mechanisms enhance the strength and ductility of Mg-3Gd
}

\author{
Xuan Luo ${ }^{1}$, Zongqiang Feng ${ }^{1,2}$, Tianbo $\mathrm{Yu}^{3}$, Junqian Luo ${ }^{1}$, Tianlin Huang ${ }^{1,2}$, Guilin $\mathrm{Wu}^{1,2, *}$, \\ Niels Hansen ${ }^{1,4}$, Xiaoxu Huang ${ }^{1,2,3, * *}$ \\ ${ }^{1}$ International Joint Laboratory for Light Alloys (MOE), College of Materials Science and \\ Engineering, Chongqing University, Chongqing 400044, China \\ ${ }^{2}$ Shenyang National Laboratory for Materials Science, Chongqing University, Chongqing 400044, \\ China \\ ${ }^{3}$ Department of Mechanical Engineering, Technical University of Denmark, DK-2800 Kgs. Lyngby, \\ Denmark \\ ${ }^{4}$ Technical University of Denmark, Risø Campus, DK-4000 Roskilde, Denmark \\ * Corresponding author, Email: wugl@cqu.edu.cn \\ ** Corresponding author, Email: xihu@mek.dtu.dk
}

\begin{abstract}
Samples of Mg-3Gd (wt. \%) were prepared by accumulative roll-bonding followed by annealing at different temperatures to produce samples with average grain sizes ranging from $3.3 \mu \mathrm{m}$ to $114 \mu \mathrm{m}$. The samples were tensile-tested at room temperature to characterize their strength and ductility, both of which were found to be significantly affected by transitions in mechanical behavior and deformation mechanisms. These transitions occurred with decreasing grain size and are described by: (i) a transition in the mechanical behavior from continuous flow to discontinuous flow associated with a yield point phenomenon, and (ii) a transition in the deformation mechanisms from $<\mathrm{a}>$ slip and twinning to $<\mathrm{a}>$ and $<\mathrm{c}+\mathrm{a}>$ slip. The dislocation structures and deformation twins in the tensile samples have been characterized by transmission electron microscopy and electron backscatter diffraction, respectively. Dislocations of $<\mathrm{a}>$ and $<\mathrm{c}+\mathrm{a}>$ type were identified based on two-beam diffraction contrast experiments. The results reveal that $<\mathrm{a}>$ dislocations and tension twins dominate in the samples with grain sizes larger than $10 \mathrm{fm}$, while $<\mathrm{a}>$ and $<\mathrm{c}+\mathrm{a}>$ dislocations dominate in the samples with grain sizes smaller than $51 \mathrm{~m}$. In parallel, a consistent trend for both the strength and ductility to increase with decreasing grain size is observed. The appearance of a yield point phenomenon at small grain sizes has a significant effect on both strength and ductility, illustrated by an increase in boundary (Hall-Petch) strengthening and an increase in the total elongation to $36.6 \%$. These results demonstrated a positive effect of a superposition of the transitions on both the
\end{abstract}


strength and ductility of $\mathrm{Mg}-3 \mathrm{Gd}$.

Keywords: Mg-3Gd alloy; Grain size; Hall-Petch relationship; $<\mathrm{c}+\mathrm{a}>$ dislocations; Twinning.

\section{Introduction}

In the research and development of strong and ductile Mg alloys, many routes have been explored encompassing a variety of processing and materials parameters $[1,2]$. Some examples of the processing routes explored include rolling $[3,4]$, extrusion $[5,6]$, and high pressure torsion (HPT) [7,8]. With regard to materials parameters, example approaches cover both the addition of alloying elements, including rare earths [9-11], as well as structural variations, such as a reduction in grain size $[3,6,12,13]$. Adding alloying elements, such as $\mathrm{Al}, \mathrm{Zn}, \mathrm{Gd}$ and $\mathrm{Y}$, into $\mathrm{Mg}$ can change the critical resolved shear stress (CRSS) ratios for different deformation modes [14-16], as well as dislocation core structures [17,18] and cross-slip ability [19-21] of multiple slip systems [18-22]. Furthermore, high ductility has frequently been reported in fine-grained $\mathrm{Mg}$ alloys, indicating that the grain size plays an important role in the activation of nonbasal slip, which is desirable for enhancement of ductility [6,22-24].

Based on an optimization of parameters and on the inherent high anisotropy of $\mathrm{Mg}$ alloys, many characteristic features, including mechanical behavior and deformation mechanisms, have been explored in Mg alloys, for example a yield point phenomenon, twinning, and non-basal slip. Each of these can provide an important contribution to the mechanical properties [25-29]. In particular, the grain size dependence of deformation mechanisms including twinning, $<\mathrm{a}>$ slip, and $<\mathrm{c}+\mathrm{a}>$ slip was investigated by slip trace analysis method using electron backscatter diffraction (EBSD) data [30,31]. Transmission electron microscopy (TEM) observations of dislocation mechanisms, such as non-basal $<\mathrm{a}>$ slip and $<\mathrm{c}+\mathrm{a}>$ slip, were also carried out recently [9,29,31-35]. However, there are still only limited data regarding statistical TEM-based analyses of the activation of different slip systems, especially in fine-grained samples where optimized mechanical properties can be obtained.

In the present study, a Mg-3Gd alloy is investigated with grain size as the key variable. 
The average grain size is varied over a wide range, which allows transitions in mechanical behavior and deformation mechanisms to be evaluated. Transitions in both are found to occur with decreasing grain size and cover: (i) a transition in the mechanical behavior from continuous flow to discontinuous flow, associated with a yield point phenomenon, and (ii) a transition in the deformation mechanisms from $<\mathrm{a}>$ slip and twinning to a combination of $<\mathrm{a}>$ and $<\mathrm{c}+\mathrm{a}>$ slip. The investigation of the mechanical behavior is performed by tensile testing with a focus on the yield strength, the yield point phenomenon, the work hardening rate and the uniform and total elongation. The microstructures are characterized by electron microscopy techniques with a focus on identification of the different deformation mechanisms. The discussion will cover the microstructural evolution as affected by the deformation mode, the strengthening mechanisms, with focus on Hall-Petch strengthening, and the enhanced ductility in terms of uniform and total elongation.

\section{Experimental}

A Mg-3Gd (wt.\%) ingot with a diameter of $100 \mathrm{~mm}$ was prepared by casting, followed by homogenization treatment at $450{ }^{\circ} \mathrm{C}$ for $24 \mathrm{~h}$. The homogenized ingot was hot extruded to a plate with a thickness of $3 \mathrm{~mm}$ and then hot rolled to $1 \mathrm{~mm}$ at $450{ }^{\circ} \mathrm{C}$, followed by annealing at $500{ }^{\circ} \mathrm{C}$ for $3 \mathrm{~h}$ to produce initial sheet samples with an equiaxed recrystallized grain structure. The grain structure of this initial state was investigated using EBSD and is shown in Fig. 1a. The grain size was measured as about $45 \mu \mathrm{m}$. Specimens with a length of $70 \mathrm{~mm}$ and a width of $25 \mathrm{~mm}$ were prepared from the initial $1 \mathrm{~mm}$ thick sheet samples for processing using accumulative roll-bonding (ARB) [36,37]. Two such specimens were stacked and preheated at $400{ }^{\circ} \mathrm{C}$ for $8 \mathrm{~min}$, and then roll bonded. The ARB processing was repeated without lubrication for two cycles with the rolling direction (RD) kept fixed during each rolling treatment. The ARB-processed specimens were then annealed at different temperatures in the range of $310^{\circ} \mathrm{C}$ to $550{ }^{\circ} \mathrm{C}$ for $1-2 \mathrm{~h}$ followed by quenching into cold water to prepare samples with average grain sizes covering a wide range from $3.3 \mu \mathrm{m}$ to $114 \mu \mathrm{m}$. No precipitates were observed in any of the samples. Examples of the microstructures of the samples with average grain sizes of $3.3 \mu \mathrm{m}$ and $6.3 \mu \mathrm{m}$ are shown in Figs. $1 \mathrm{~b}$ and c, respectively. Fig. 1d illustrates the similar distributions of misorientation angles for the above 
described samples, all showing a very low fraction of low angle boundaries. Analysis of the textures from the EBSD measurements showed a similar weak basal texture in all the annealed samples with different grain sizes.

Dog-bone-shaped tensile specimens with a gauge length of $13 \mathrm{~mm}$ and a cross-section of $5 \times 1 \mathrm{~mm}^{2}$ were cut, with the tensile direction parallel to the RD. Uniaxial tensile testing was performed using an AGX-50 system at an initial strain rate of $8.3 \times 10^{-4} \mathrm{~s}^{-1}$ at room temperature. A laser extensometer was used to measure the strain during loading. For each sample condition, three tensile specimens were tested.

Microstructural characterization was carried out with a Zeiss Auriga scanning electron microscope (SEM) equipped with an Oxford AZtec EBSD detector, and using a JEM2100 transmission electron microscope operated at $200 \mathrm{kV}$. Samples for SEM investigations were prepared by mechanical polishing followed by electrochemical polishing in an AC2 solution, composed of $800 \mathrm{ml}$ ethanol, $100 \mathrm{ml}$ propanol, $15 \mathrm{ml}$ perchloric acid, $18.5 \mathrm{ml}$ distilled water, $10 \mathrm{~g}$ hydroxyquinoline, $75 \mathrm{~g}$ citric acid and $41.5 \mathrm{~g}$ sodium thiocyanate. Thin foils for TEM observations were prepared by ion milling using a Gatan PIPS 691 instrument. Samples for TEM were cut from the uniformly deformed gauge section of the tested tensile samples such that the observation plane was the section containing the RD (and hence the tensile axis) and the normal direction (ND) of the initial rolled sheet. 

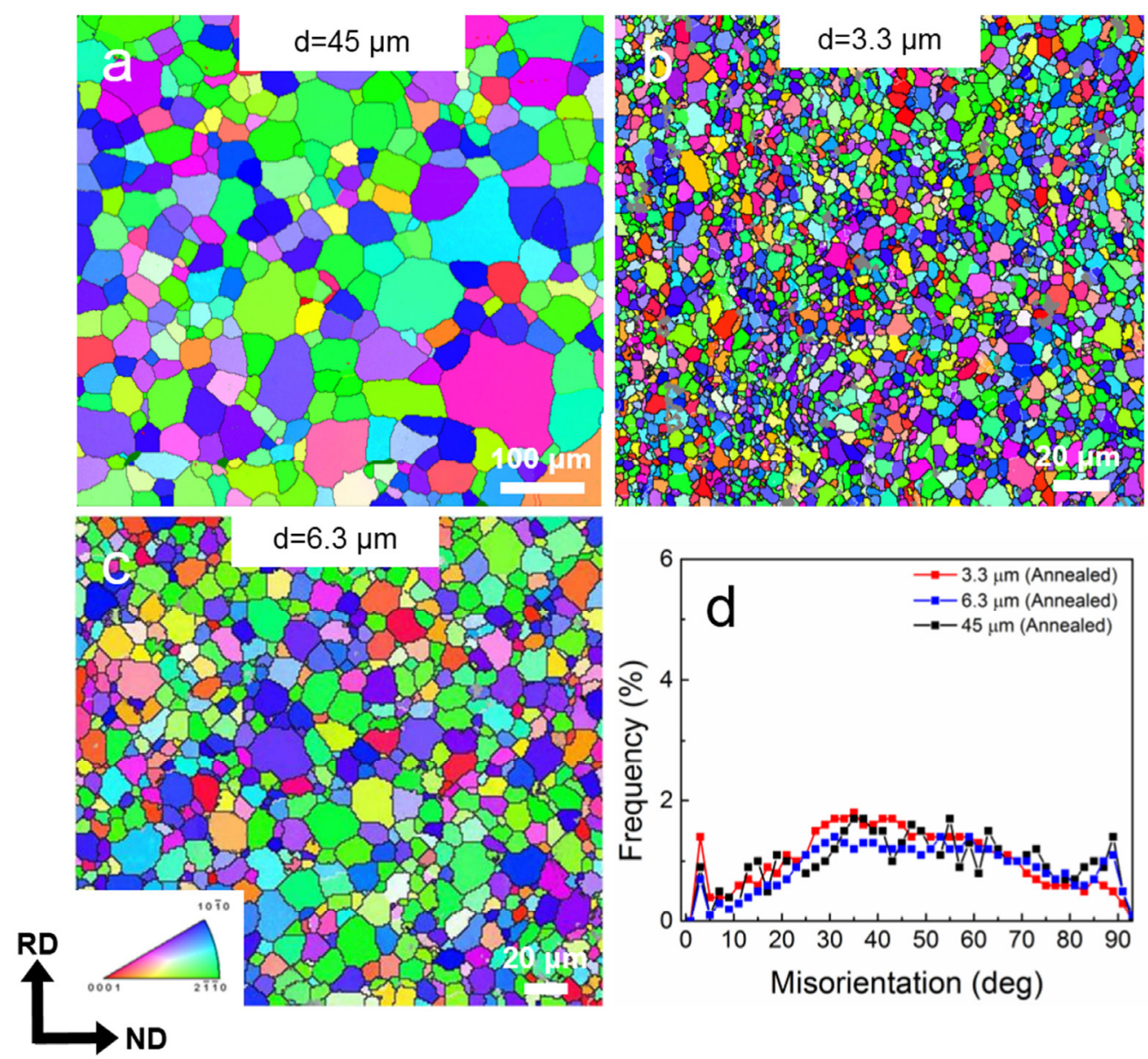

Fig. 1. EBSD images showing the grain structures of (a) the initial sheet sample before ARB processing, and $(\mathrm{b}, \mathrm{c})$ two fine-grained samples produced by ARB processing followed by annealing for $1 \mathrm{~h}$ at $(\mathrm{b})$ $310^{\circ} \mathrm{C}$ and (c) $360^{\circ} \mathrm{C}$. (d) Misorientation angle distributions of the three samples shown in (a-c).

The TEM foils were used to analyze dislocation structures within individual grains in the tested tensile samples. Images for this analysis were taken under two-beam diffraction conditions using different diffraction $\boldsymbol{g}$ vectors. Table 1 shows the three selected $\boldsymbol{g}$ vectors [0002], [20] and [112] used in this study, all of which are all associated with the [010] zone axis, and also shows the corresponding $\boldsymbol{g} \cdot \boldsymbol{b}$ analysis for the two types of Burgers vectors in Mg, $<\mathrm{a}>$ and $<\mathrm{c}+\mathrm{a}>$. The $\boldsymbol{g} \cdot \boldsymbol{b}$ analysis shows that $<\mathrm{a}>$ dislocations are invisible for $\boldsymbol{g}=[0002]$ and both $<\mathrm{a}>$ and $<\mathrm{c}+\mathrm{a}>$ dislocations are visible at $\boldsymbol{g}=[20]$, while dislocations of all Burgers vectors are visible at $\boldsymbol{g}=[112]$, except for $\boldsymbol{b}=[11]$. Clearly, the use of these three selected $\boldsymbol{g}$ reflections allows an identification of the dislocation type ( $<\mathrm{a}>$ and $<\mathrm{c}+\mathrm{a}>$, rather the individual Burgers vectors) in $\mathrm{Mg}$. Combined with an analysis of slip plane traces, basal $<\mathrm{a}>$ and non-basal $<\mathrm{a}>$ dislocations can also be identified. 
Table 1 Diffraction vectors used for analysis of the dislocation types in $\mathrm{Mg}$

\begin{tabular}{c|c|c|c|c|c|c|c|c|c}
\hline \multirow{2}{*}{$\boldsymbol{g}$} & \multicolumn{7}{c}{$\boldsymbol{g} \cdot \boldsymbol{c}$} \\
\cline { 2 - 10 } & \multicolumn{3}{|c|}{$<\mathrm{a}>$} & \multicolumn{7}{c}{$<\mathrm{c}+\mathrm{a}>$} \\
\cline { 2 - 10 } & {$[110]$} & {$[20]$} & {$[110]$} & {$[11]$} & {$[23]$} & {$[113]$} & {$[11]$} & {$[2]$} & {$[11]$} \\
\hline$[0002]$ & $\times$ & $\times$ & $\times$ & $\sqrt{ }$ & $\sqrt{ }$ & $\sqrt{ }$ & $\sqrt{ }$ & $\sqrt{ }$ & $\sqrt{ }$ \\
\hline$[20]$ & $\sqrt{ }$ & $\sqrt{ }$ & $\sqrt{ }$ & $\sqrt{ }$ & $\sqrt{ }$ & $\sqrt{ }$ & $\sqrt{ }$ & $\sqrt{ }$ & $\sqrt{ }$ \\
\hline$[112]$ & $\sqrt{ }$ & $\sqrt{ }$ & $\sqrt{ }$ & $\sqrt{ }$ & $\sqrt{ }$ & $\sqrt{ }$ & $\sqrt{ }$ & $\sqrt{ }$ & $\times$ \\
\hline
\end{tabular}

$(\sqrt{ }$ : visible, $:$ invisible $)$

\section{Results and analysis}

\subsection{Mechanical behavior}

Fig. 2 shows the engineering stress-strain curves of the samples with grain sizes ranging from $3.3 \mu \mathrm{m}$ to $114 \mu \mathrm{m}$. Also included is the stress-strain curve (in black) of the initial sample (grain size of $45 \mu \mathrm{m}$ ). It is seen that the coarse-grained samples, defined as those with grain sizes ranging from $114 \mu \mathrm{m}$ to $12 \mu \mathrm{m}$, show typical smooth stress-strain curves, while the fine-grained samples, with smaller grain sizes from $12 \mu \mathrm{m}$ to $3.3 \mu \mathrm{m}$, show a yield point followed by Lüders elongation. Following the conventional definition [38], the stress-strain behavior in the coarse-grained samples can be described as continuous, and that in the fine-grained samples as discontinuous. Clearly, with decreasing grain size, a transition in stress-strain curve takes place from continuous to discontinuous flow associated with a yield point phenomenon. It is also seen that the decrease in the grain size range of $114 \mu \mathrm{m}$ to $12 \mu \mathrm{m}$ is associated with an increase in strength and a moderate increases in elongation. A substantial increase in both total elongation and yield strength occurs, however, with a decrease in the grain size from $6.3 \mu \mathrm{m}$ to $3.3 \mu \mathrm{m}$. Table 2 summaries the mechanical properties obtained from the stress-strain curves of all the tested samples. 


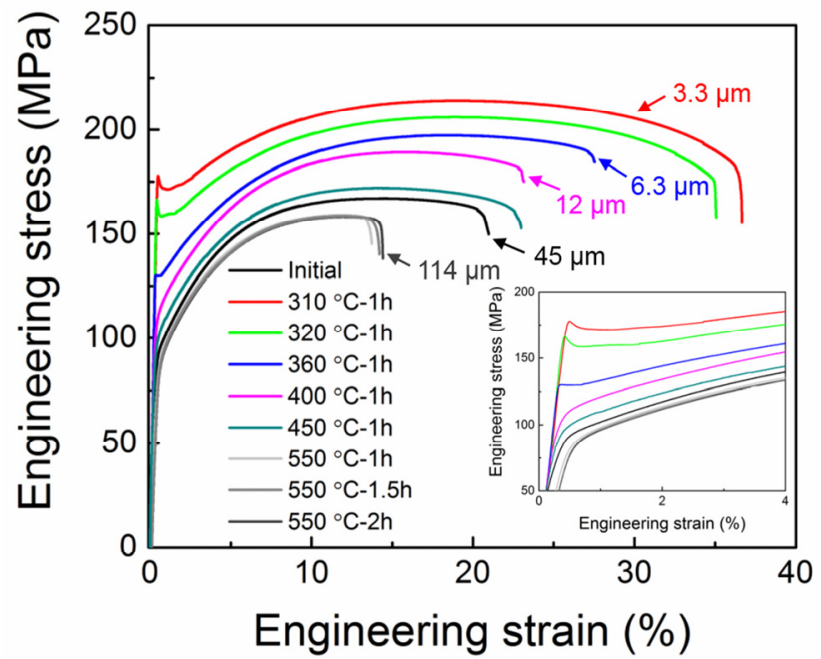

Fig. 2. Engineering stress-strain curves of the initial sample before ARB (grain size: $45 \mu \mathrm{m}$ ) and for samples of different average grain sizes obtained by ARB-processing and annealing under different conditions.

The effect of grain size on the yield stress ( $0.2 \%$ offset) is plotted in accordance with the Hall-Petch relationship in Fig. 3a. This relationship has previously been demonstrated to hold for $\mathrm{Mg}$ and $\mathrm{Mg}$ alloys, although large variations in the Hall-Petch parameters have been found [12,39-43]. Fig. 3a also shows that such variations appear to be significantly dependent on the grain size. For large grain sizes $(>12 \mu \mathrm{m})$ the experimental data follow a Hall-Petch relationship of the form:

$$
\sigma_{(0.2)}=71.9+144.4 d^{-0.5}
$$

Table 2. Mechanical properties of annealed samples.

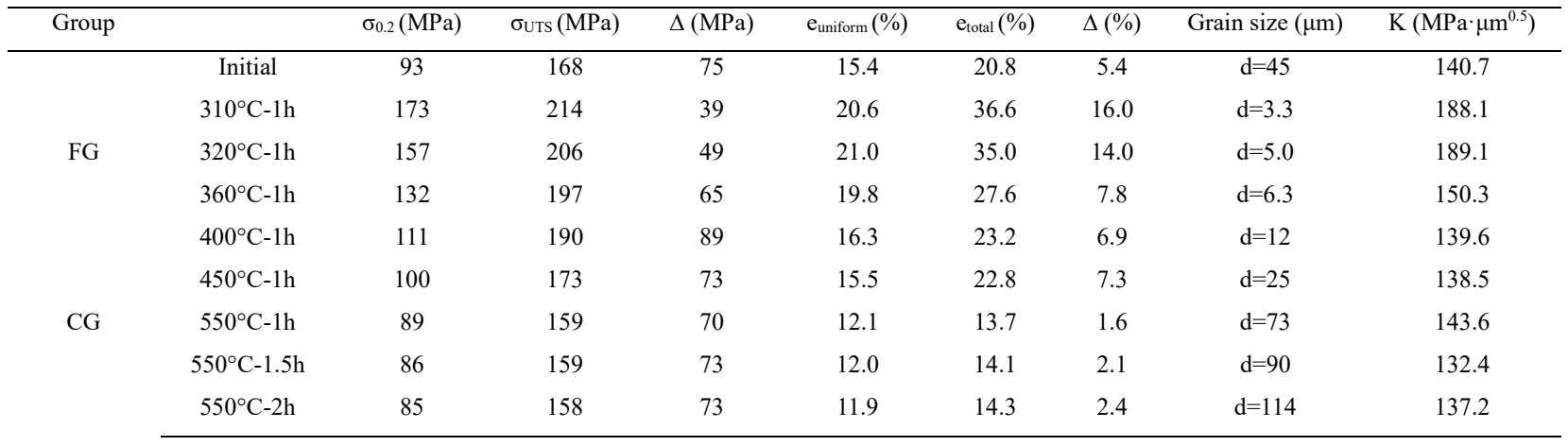

This equation is valid for large grain sizes but breaks down at small grain sizes, where a significant increase in the Hall-Petch slope is observed, see Table 2. This grain size effect has also been found in other fine-grained metals characterized by a yield point phenomenon, e.g., IF steel $[44,45]$, aluminium [46,47,48] and copper [49]. In these 
studies, the strength increase has been related to a lack of dislocation sources $[47,50]$ thus requiring an extra stress to activate dislocation sources and plastic deformation. In Fig. 3a, the yield stress $\sigma_{0.2}$ is plotted versus the reciprocal square root of the grain size, where a transitional stage is observed in the grain size range of $5-10 \mu \mathrm{m}$, in which the Hall-Petch slope increases to about $190 \mathrm{MPa} \cdot \mu \mathrm{m}^{0.5}$. The elongation also changes significantly in this transitional range, as seen in Fig. 3b. In this figure, the uniform and total elongations are plotted versus the reciprocal square root of the grain size to give a better impression of changes taking place in the transitional stage. Fig. $3 \mathrm{~b}$ shows that the elongation increases with a decrease in grain size, highlighting the marked increase in total elongation to about $36.6 \%$ at the finest grain size of $3.3 \mu \mathrm{m}$ examined.
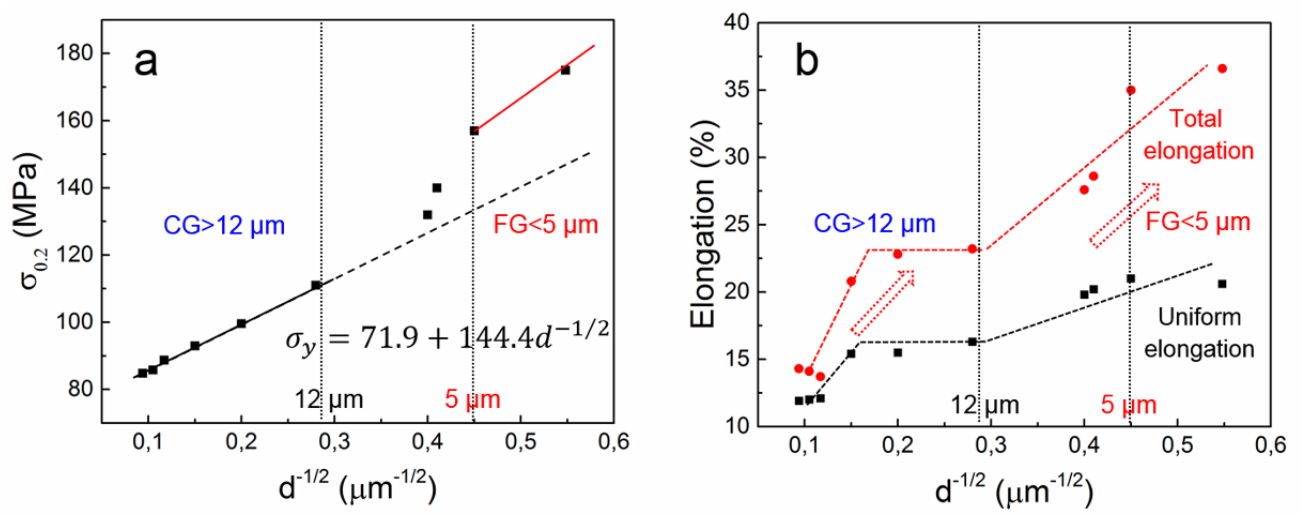

Fig. 3. (a) Hall-Petch relationship of Mg-3Gd samples, (b) The relationship between elongation and grain size.

\subsection{Microstructure}

To understand the transition in the mechanical behavior of different grain-sized samples, EBSD and TEM observations were carried out to analyze the grain size effect on deformation mechanisms during tensile straining. Note that EBSD and TEM were used to analyze twinning, and TEM was used to identify the active dislocation types in the finest grain-size sample $(\mathrm{d}=3.3 \mu \mathrm{m})$.

\subsubsection{EBSD observations}

EBSD observations of coarse-grained and fine-grained samples after an applied tensile strain of 5\% are shown in Fig. 4, where boundaries with misorientation angles above $15^{\circ}$ (high angle boundaries, HABs) and between $2^{\circ}$ to $15^{\circ}$ (low angle boundaries, $\mathrm{LABs}$ ) are indicated by black and white lines, respectively. As shown in Fig. 4a, many 
twins (marked by red arrows) are formed in the coarse-grained sample $(\mathrm{d}=45(\mathrm{~m})$ and in some large grains in the sample with 6.3 / $\mathrm{m}$ grain size, with few LABs in the coarsegrained sample. In contrast, many LABs are found in the fine grain-sized samples (Figs. $4 \mathrm{~b}$ and c). Fig. $4 \mathrm{~d}$ shows the misorientation angle distributions, showing that $5 \%$ deformation increases the frequency of LABs in both the coarse- and fine-grained samples. A big difference, however, is the significant amount of $\{102\}$ tension twinning (corresponding to the misorientation angle peak of $86^{\circ}$ ) in the coarse-grained sample. Analysis of pole figures from the EBSD measurements also showed that orientations corresponding to tension twinning were formed extensively in the coarse-grained samples but not in the fine-grained samples, even though these samples had a similar initial basal texture. This difference in textural evolution is a manifestation of a grain size effect on the deformation mechanisms.

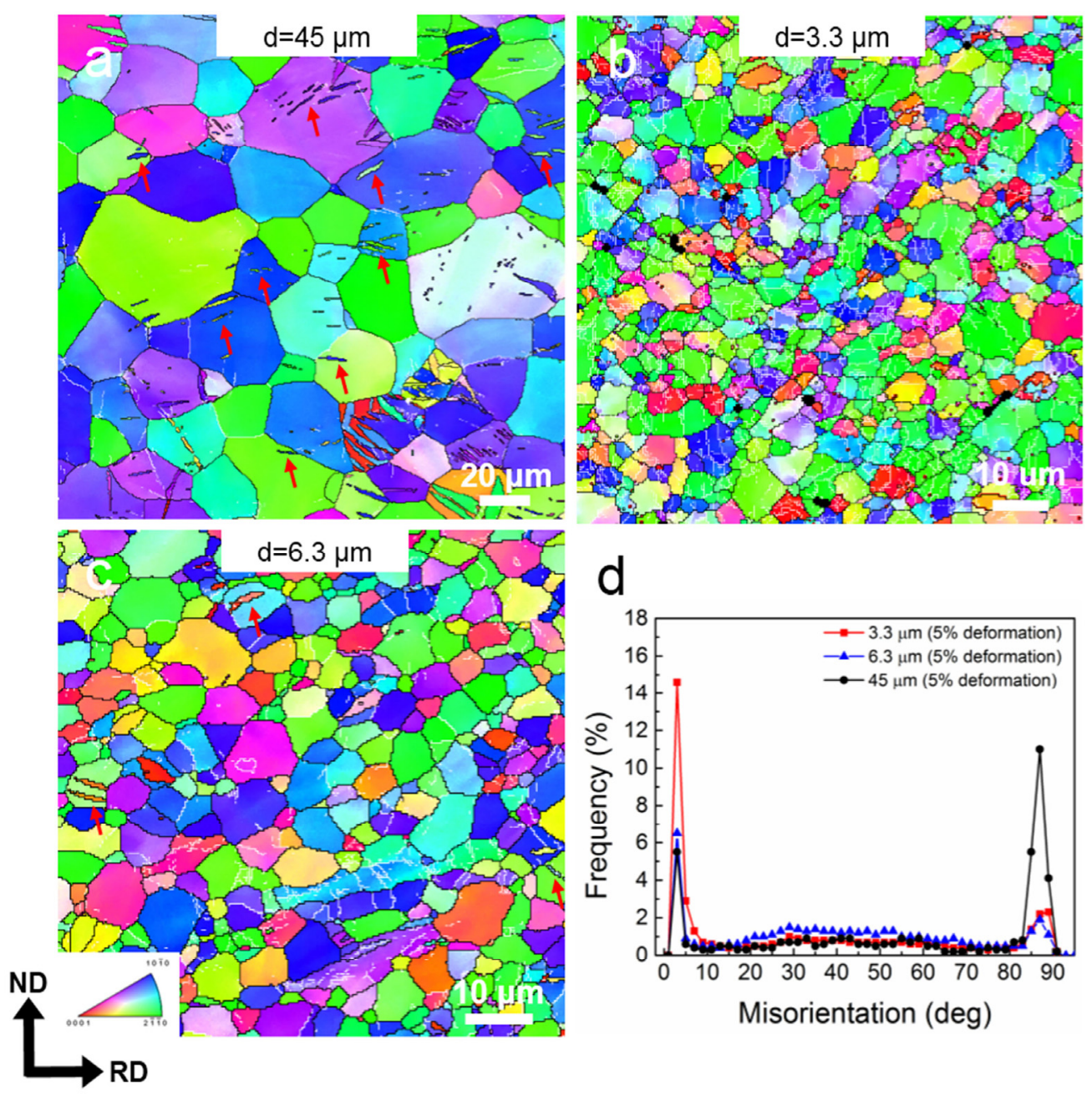

Fig. 4. EBSD images showing the 5\% tensile-deformed structures of (a) the initial sheet sample and (b, 
c) two fine-grained samples. (d) Misorientation angle distributions of the three samples shown in (a-c).

\subsubsection{TEM observations}

To further analyze the grain size dependence of the deformation mechanisms, coarsegrained and fine-grained samples tensile deformed to failure were characterized in detail. In addition, a fine-grained sample deformed to a tensile strain of $5 \%$ was also characterized.

Fig. 5 shows TEM images of the 45 / $\mathrm{m}$ grain-sized sample tensile deformed to failure. As shown in Fig. 5a, a high density of basal $<\mathrm{a}>$ dislocations are present in the coarse grain. A narrow deformation twin $\left(<1 \int \mathrm{m}\right.$ wide) is also seen inside a coarse grain in addition to the $<\mathrm{a}>$ dislocations, as shown in Fig. 5b. Based on an analysis of the selected area electron diffraction pattern (see the inset in Fig. 5b), this twin is a tension twin $\left(86^{\circ} /[110]\right)$. Parallel stacking faults (SFs) are also observed within the deformation twin. No $<\mathrm{c}+\mathrm{a}>$ dislocations were observed, however, in any of the grains examined in this sample deformed to failure.
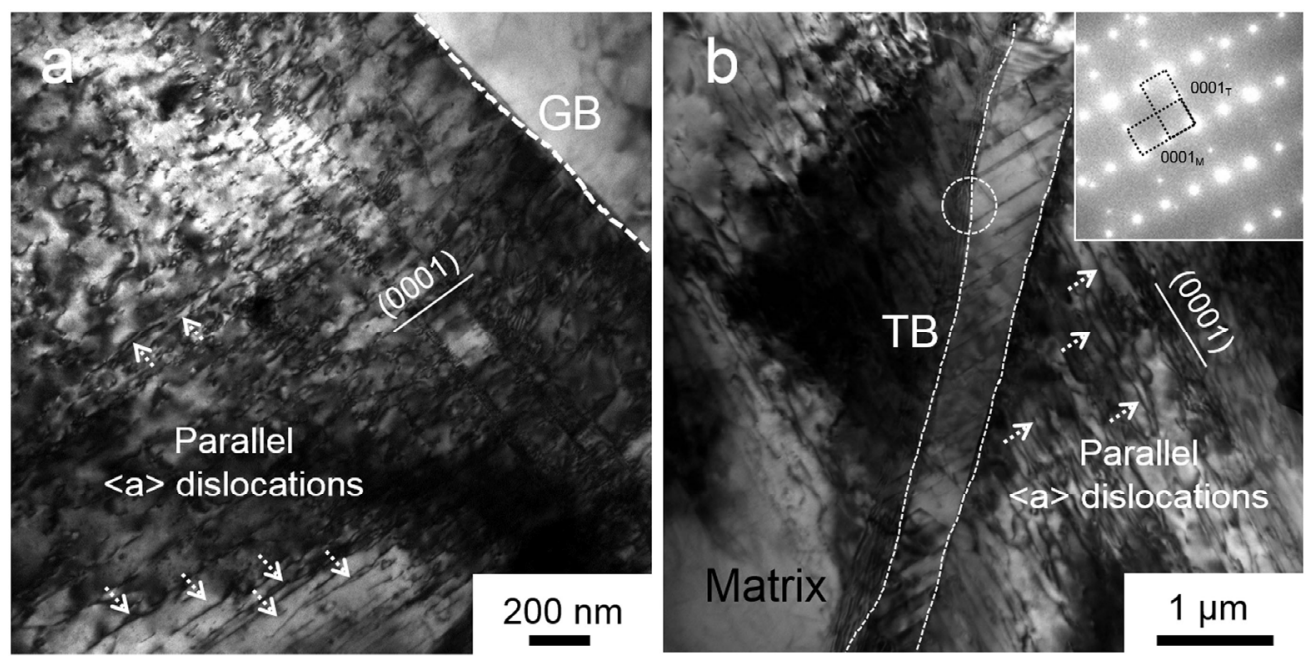

Fig. 5. TEM images taken from the uniformly deformed gauge section of the $45 / \mathrm{m}$ grain-sized sample tensile-deformed to failure (corresponding to a tensile strain of $\sim 15 \%$ ) showing the activation of basal $<\mathrm{a}>$ slip and deformation twinning.

Fig. 6 shows TEM images of the 3.3 /m grain-sized sample deformed to a tensile strain of 5\%. Figs. $6 \mathrm{a}$ and $\mathrm{b}$ show the two-beam bright field and dark field images with $\boldsymbol{g}=[0002]$ near the [010] zone axis. Many dislocations are seen (examples are indicated by red arrows) inside the grain; all these dislocations were determined to be $<c+a>$ type 
based on the $\boldsymbol{g} \bullet \boldsymbol{b}$ analysis shown in Table 1. Fig. 6c shows a two-beam bright field image taken using $\boldsymbol{g}=[20]$ near the [010] zone axis, revealing more dislocations in this area. In addition to the $<\mathrm{c}+\mathrm{a}>$ dislocations, corresponding to those seen in Figs. 6a and b, many $<\mathrm{a}>$ dislocations are also identified (examples are marked by white dashed arrows). The $<\mathrm{a}>$ dislocations in the upper corner region, marked by a white frame, are more clearly reveled in the dark field image (Fig. 6d), where the basal plane trace is marked by a white solid line.
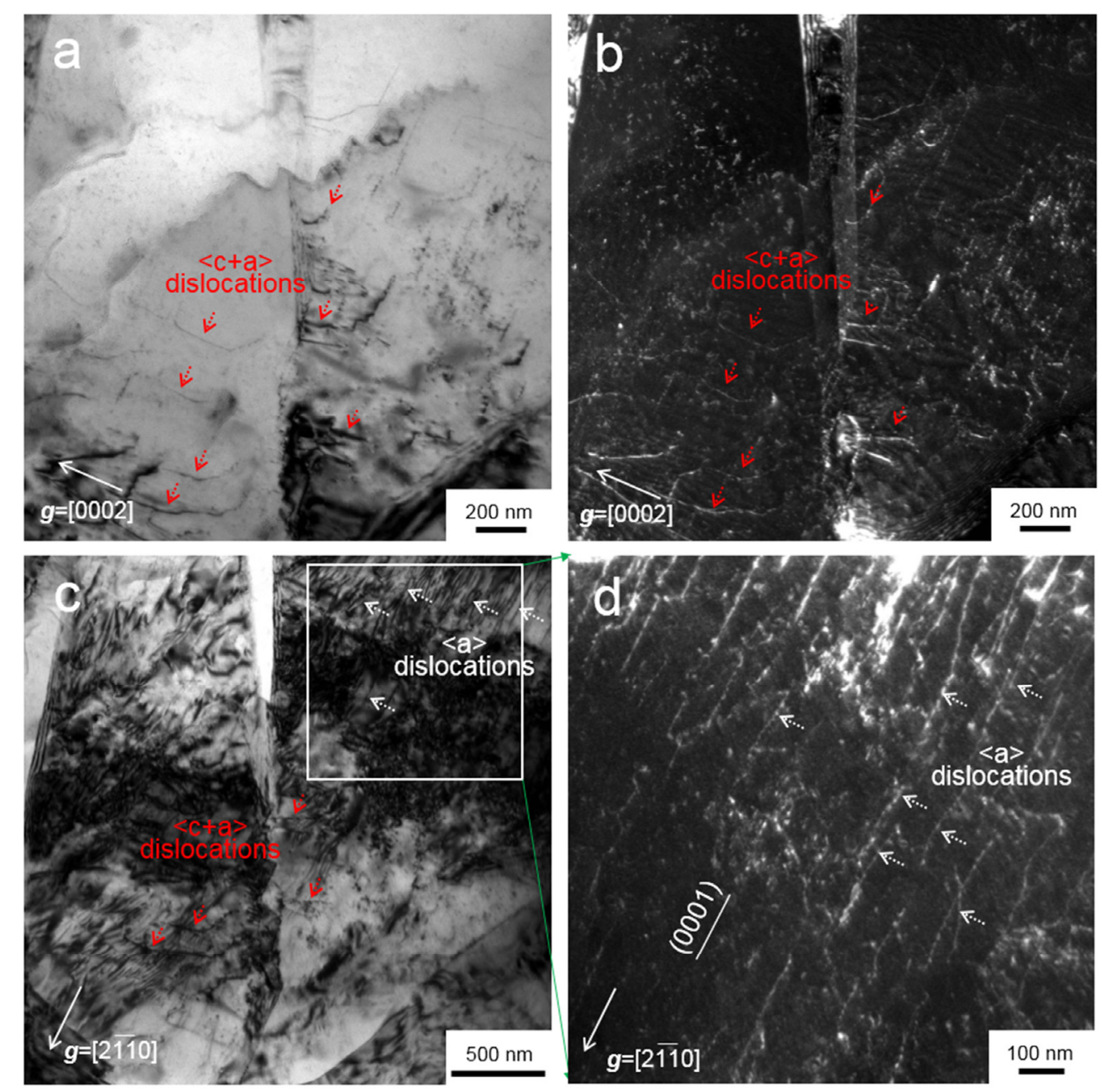

Fig. 6. Bright field and dark field TEM images of the $3.3 \int \mathrm{m}$ grain-sized sample after $5 \%$ tensile deformation using diffraction vectors of (a, b) $\boldsymbol{g}=[0002]$, and (c, d) $\boldsymbol{g}=[20]$. 

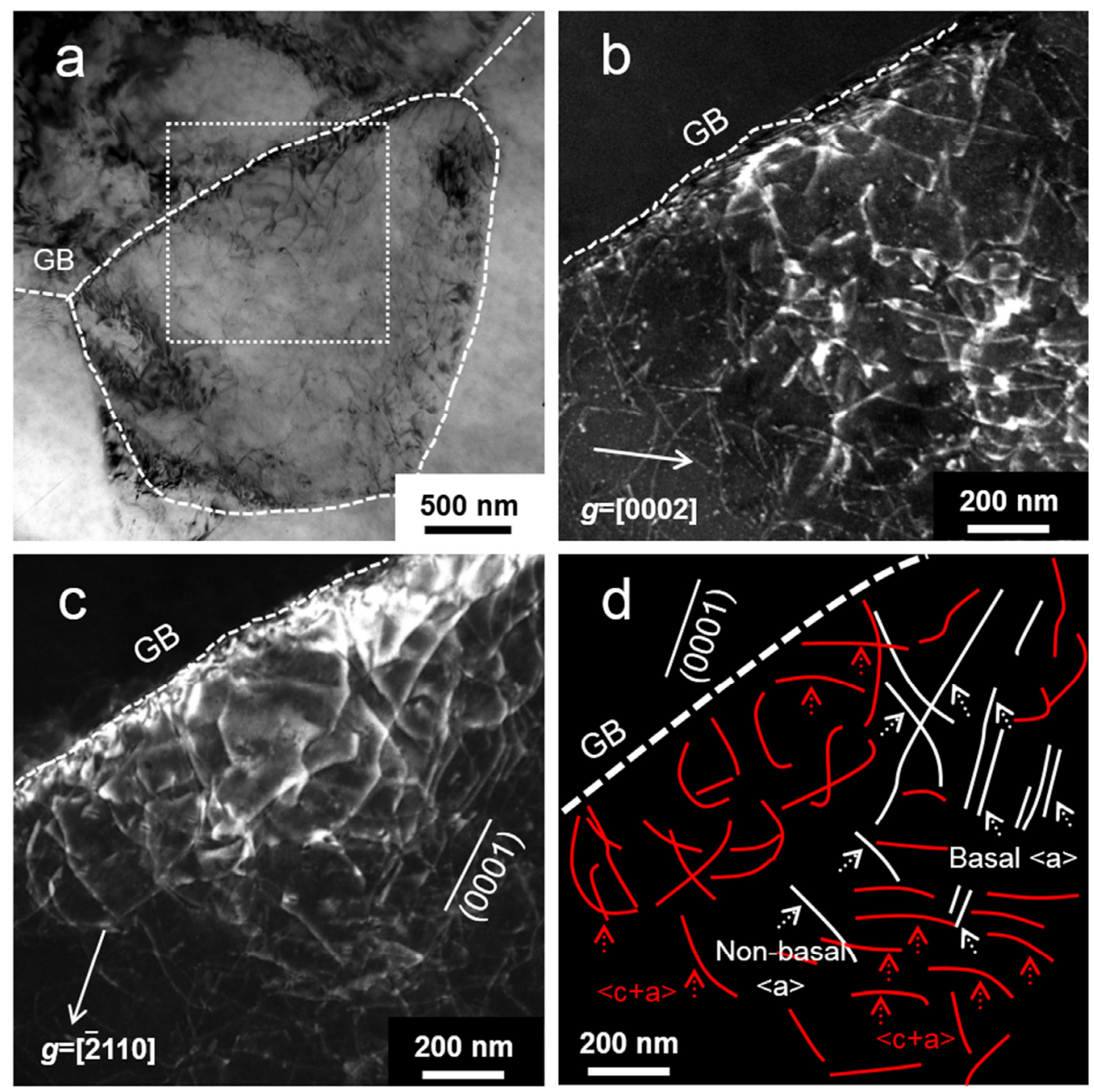

Fig. 7. Analysis of the dislocation structure in the uniformly deformed gauge section of $3.3 / \mathrm{m}$ grainsized sample tensile deformed to failure (corresponding to a tensile strain of $\sim 20 \%$ ). (a) TEM bright field image taken with the electron beam direction of approximately parallel to the [010] zone axis showing the presence of many dislocations in the grain. (b, c) Two-beam dark field images using $\boldsymbol{g}=$ [0002] and $\boldsymbol{g}=[110]$, respectively, from the area indicated by the dotted frame in (a). (d) A sketch showing the identification of $<\mathrm{a}>$ and $<\mathrm{c}+\mathrm{a}>$ dislocations in the examined area.

Fig. 7 shows an example of the dislocation structure analysis for the sample with $d=$ $3.31 \mathrm{~m}$ average grain size, tensile deformed to failure. Fig. 7a shows a bright field image taken with the electron beam approximately parallel to the [010] zone axis of the grain in the center of the image. A high density of dislocations can be seen within the grain interior. A more detailed analysis of the dislocation types was made for the area marked by a dotted frame. Figs. $7 \mathrm{~b}$ and $\mathrm{c}$ show two-beam dark field images using two different $\boldsymbol{g}$ vectors (see Table 1). A majority of the dislocations are visible in both dark field images, and can therefore be identified as $<\mathrm{c}+\mathrm{a}>$ type based on the $\boldsymbol{g} \cdot \boldsymbol{b}$ analysis shown 
in Table 1. These $<\mathrm{c}+\mathrm{a}>$ dislocations are shown as red lines in the sketch in Fig. $7 \mathrm{~d}$. In addition to the $<\mathrm{c}+\mathrm{a}>$ dislocations, several more dislocations are seen in Fig. $7 \mathrm{c}$ that are out of contrast in Fig. 7b. These dislocations were therefore identified as $<a>$ dislocations, and are indicated by white lines in Fig. 7d. Furthermore, a comparison between the dislocation line directions and the trace of the basal plane allows a separation of the observed $<\mathrm{a}>$ dislocations into basal $<\mathrm{a}>$ and non-basal $<\mathrm{a}>$ dislocations, as indicated in Fig. 7d. A majority of the dislocations stored in this grain have Burgers vector of $<\mathrm{c}+\mathrm{a}>$ type, indicating the important role played by $<\mathrm{c}+\mathrm{a}>$ slip during tensile deformation of this fine-grained sample.

\subsection{Transition in deformation mechanisms}

In total, 217 grains (85 grains from TEM and 132 grains from EBSD) were analyzed to identify the deformation mechanisms and the dislocation types. These results are

summarized in Fig. 8. In the tensile-deformed samples, $<a>$ dislocations are observed in all grains. Dislocations of $<\mathrm{c}+\mathrm{a}>$ type, together with $<\mathrm{a}>$ dislocations, are only found in fine grains smaller than $10 \mu \mathrm{m}$, and twins are present in the deformed structure, together with dislocations of basal $<\mathrm{a}>$ type, in grains coarser than $10 \mu \mathrm{m}$. It should be noted, however, that a small grain size seen in a 2D-EBSD or TEM observation may represent the intersection of a small region of a coarse grain. A small number of twins may therefore also be present in the $3.3 \mu \mathrm{m}$ sample. In Fig. 8, a transitional stage (5 $10 \mu \mathrm{m})$ separates the behavior of fine grains smaller than $5 \mu \mathrm{m}$ and coarse grains larger than $10 \mu \mathrm{m}$, where $<\mathrm{c}+\mathrm{a}>$ and $<\mathrm{a}>$ slip dominated in the former and twinning together with $<\mathrm{a}>$ slip dominated in the latter. 


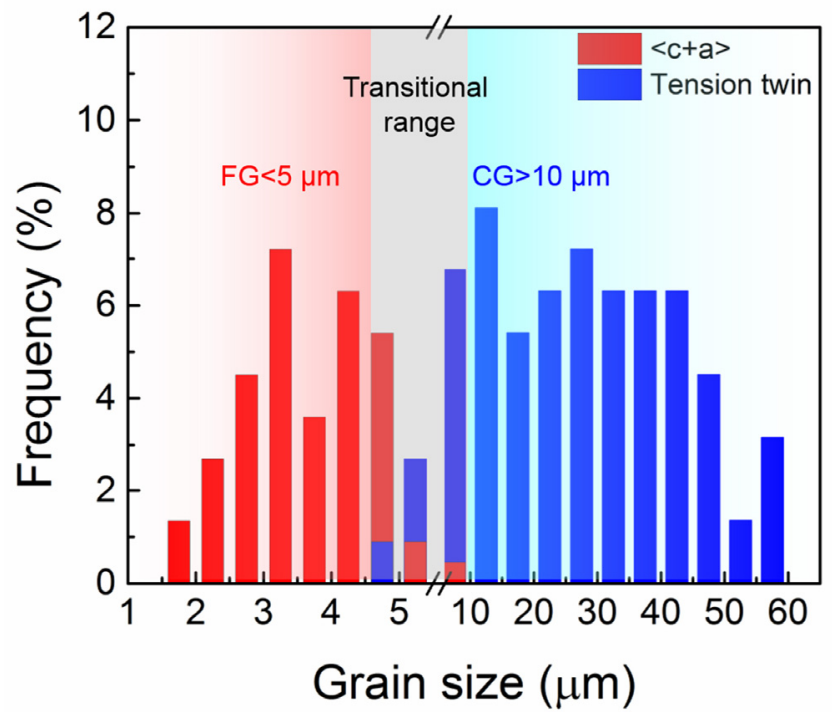

Fig. 8. Histogram showing the size distribution of grains having the $<\mathrm{c}+\mathrm{a}>$ dislocations and deformation twins observed in the Mg-3Gd samples tensile deformed to failure. Note that all grains over the entire grain size range analyzed show the activity of $<\mathrm{a}>$ dislocations, therefore not indicated in the graph for clarity.

\section{Discussion}

The microstructural evolution during plastic deformation of $\mathrm{Mg}-3 \mathrm{Gd}$ clearly shows a transition in deformation mechanisms, from $<\mathrm{a}>$ dislocation slip and twinning to $<\mathrm{a}>$ and $<\mathrm{c}+\mathrm{a}>$ dislocation slip as the grain size decreases in the interval from 114 to $12 / \mathrm{m}$. Additionally, the mechanical behavior shows a transition from continuous to discontinuous flow, with the occurrence of a yield point phenomenon as the grain size reaches the fine grain size range $(<12(\mathrm{~m})$. The following discussion will fall in two sections: (i) the effect of grain size on the structure and mechanical behavior in the grain size range 114 to 12 (m, and (ii) the effect of discontinuous flow on the structure and mechanical behavior in the grain size range from 3.3 to $121 \mathrm{~m}$.

\subsection{Grain size range 114 to 12 / $\mathrm{m}$}

The transition from $<\mathrm{a}>$ dislocation slip and twinning to $<\mathrm{a}>$ and $<\mathrm{c}+\mathrm{a}>$ dislocation slip based plasticity in Mg-3Gd has been observed in a recent experiment [37], where samples with average grain sizes of $451 \mathrm{~m}$ and $10 / \mathrm{m}$ were deformed by accumulative roll-bonding to a strain of $0.8-1.6$. By reducing the grain size, the volume fraction of twins was found to decrease from 41 to $27 \%$ and in parallel the fraction of lamellar 
dislocation boundaries and high angle boundaries increased. A more detailed structural study by TEM and EBSD of samples deformed in tension to about $20 \%$ is shown in Fig. 8. The histogram of structural features in grains of different sizes, shows a transition from $<\mathrm{a}>$ slip and twinning to $<\mathrm{a}>$ and $<\mathrm{c}+\mathrm{a}>$ slip that takes place in a grain size range of 5-10 $/ \mathrm{m}$. However, this transition does not represent an abrupt change in deformation mode. The TEM characterization shows that parameters other than grain size may have an effect on the transition, for example, the crystallographic orientation of the grains and their neighbor-neighbor relationships [51-53].

Complementary to the experimental study in Fig. 8, the effect of grain size on the transition from $\{102\}$ twinning to dislocation slip has been investigated by a dislocation dynamics simulation [12]. The results of this simulation showed that deformation twinning exhibits a strong dependence on grain size whereas dislocation activity in an untwinned Mg polycrystal showed only weak grain size dependence. A plot of the yield stress versus the grain size, therefore, shows the presence of a critical (small) grain size above which twinning dominates, whereas for smaller grain sizes dislocation slip is the controlling mechanism [12].

The mechanical behavior of the samples examined in the present study shows a clear trend that both the strength and the ductility, expressed by the uniform/total elongation, increase with a decrease in grain size over the grain size range of 114-12 / $\mathrm{m}$. The strength can be related to the reciprocal square root of the grain size, with a Hall-Petch slope of $\sim 144 \mathrm{MPa} \cdot\left(\mathrm{m}^{0.5}\right.$ (Table 2$)$, where this slope is independent of the grain size, pointing to a comparable resistance to slip from both twin boundaries and from low angle dislocation boundaries and high angle grain boundaries.

\subsection{Grain size range $12-3.3 / \mathrm{m}$}

This grain size range represents a transition from continuous to discontinuous flow, where of special importance is the occurrence of a yield point phenomenon characterized by an upper and lower yield stress and a Lüders elongation at an almost constant stress. After the Lüders strain, the samples strain-harden to a maximum stress with a uniform elongation of approx. 20\% (see Table 2) followed by a stage where the total strain can be as high as $36.6 \%$ (at a grain size of $3.3(\mathrm{~m}$ ). In accordance with previous studies of the yield point phenomenon $[45,46]$, the present study shows that the Lüders elongation increases with a decrease in grain size to reach a strain of 1 to 
$2 \%$.

The yield point phenomenon points to a lack of mobile dislocations, which may be absent or be strongly pinned. In the $\mathrm{Mg}-3 \mathrm{Gd}$, solutes are present which may pin the dislocations [26]. However, as the yield point phenomenon is not observed at grain sizes larger than $12 \mathrm{~lm}$, the present observations are best interpreted as a lack of mobile dislocations, where these have been annihilated during the thermomechanical processing to give a structure with a high concentration of boundaries that can act as dislocation sinks. To initiate plastic deformation in these fine-grained samples, dislocation sources must therefore be activated, requiring an extra source-stress, and providing an additional strengthening mechanism [47,50]. The high yield stress is reflected in the significant increase in the Hall-Petch slope (see Table 2). This effect is in accord with previous experiments of fine-grained $\mathrm{Al}[46,47,48]$, IF steel $[44,45]$ and copper [49].

A high concentration of dislocations may be stored in the structure during propagation of the Lüders strain, which may cause formation of pile-ups at the narrowly spaced grain boundaries and a continuance of plastic flow by activation of sources at the front of the pile-ups [54-56]. An estimate of the dislocation density after propagation of the Lüders strain can be obtained based on the value for the lower yield stress assuming Taylor strengthening, i.e. $\sigma \sim \rho^{0.5}$. This density is high and of the order of $10^{14} \mathrm{~m}^{-2}$. The existence of such a high dislocation density is demonstrated in Fig. 6 showing the microstructure in a sample deformed to $5 \%$ in tension, i.e. just slightly beyond the Lüders region.

An important observation is the very large increase in total elongation, which follows a reduction in grain size to $3.3 \mathrm{fm}$ (see Table 2). The total elongation combines a uniform elongation to the maximum strength, followed by necking and a reduction in the flow stress. The necking mechanisms appear to be depend significantly on the grain size. This is illustrated in Fig. 9 showing tensile samples after testing to fracture. All samples show the presence of necking. However, for a small grain size $(3.3 / \mathrm{m})$, the necking is in the form of a reduction in the cross-section area of the sample. However, for the larger grain size sample $(\sim 12\lceil\mathrm{~m})$ the necking is more localized. As a tentative hypothesis, it is suggested that the dislocation structures developed during Lüders 
elongation, combined with the high yield stress, facilitate the activation of $<\mathrm{c}+\mathrm{a}>$ dislocations during further tensile straining. As a consequence, the dislocation density increases remarkably with strain, which may enhance both strain hardening and the strain hardening rate, leading to high total elongation (Fig. 9).
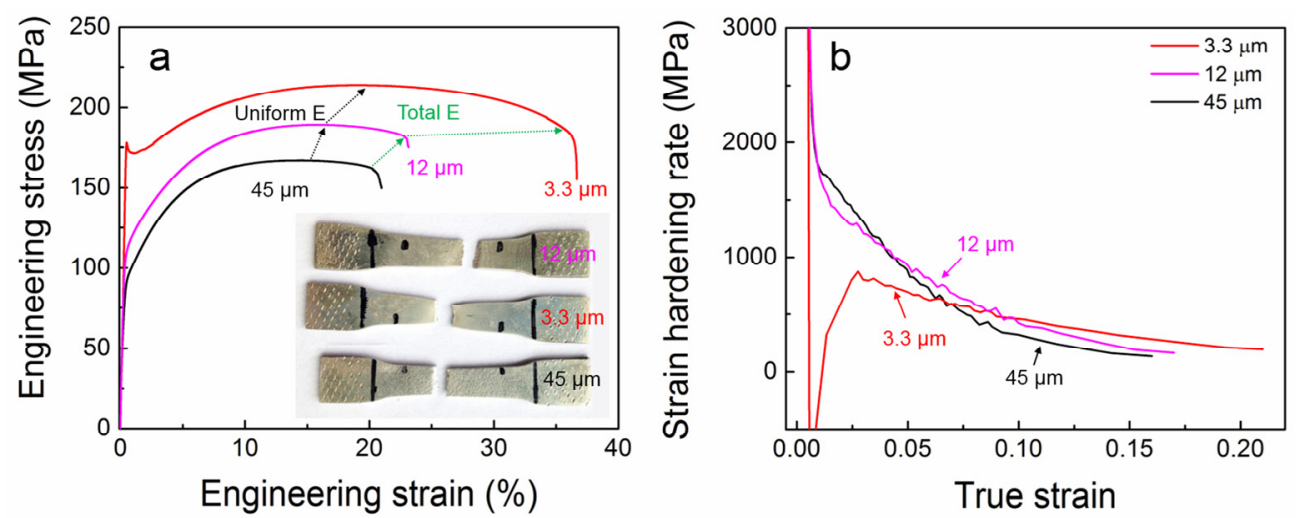

Fig. 9. Tensile samples after testing to fracture (a) and corresponding strain hardening rate (b).

In summary, the high density of dislocations encompassing both $<\mathrm{c}+\mathrm{a}>$ and $<\mathrm{a}>$ dislocations (see Fig. 6 and Fig. 7) suggests that a change in slip mode following a reduction of grain size may be the cause of the enhanced strength and ductility seen in the fine-grained Mg-3Gd alloy [9,22,57-59]. These findings point to further research including characterization of strength and formability of alloys with a grain size approaching the sub-micrometer dimension.

\section{Conclusions}

The effect of grain size on the transition from $<\mathrm{a}>$ slip and twinning to $<\mathrm{a}>$ and $<\mathrm{c}+\mathrm{a}>$ slip based plasticity has been investigated by tensile deformation of $\mathrm{Mg}-3 \mathrm{Gd}$ samples with different grain sizes in the range of 3.3 to $114 \mu \mathrm{m}$. The conclusions as follows:

1. There is a clear trend in the grain size range investigated that both the strength and elongation increase with a decrease in grain size.

2. Grains with sizes larger than $10 \mu \mathrm{m}$ deform by the activation of $<\mathrm{a}>$ slip and twinning, whereas grains with sizes smaller than $5 \mu \mathrm{m}$ deform by a combination of $<\mathrm{a}>$ and $<\mathrm{c}+\mathrm{a}>$ slip. A transitional stage of deformation mechanism from $<\mathrm{a}>$ slip and 
twinning to $<\mathrm{a}>$ and $<\mathrm{c}+\mathrm{a}>$ slip is observed in the grain size range 5-10 $\mu \mathrm{m}$. A corresponding transitional stage in mechanical behavior from continuous flow to discontinuous flow is initiated at a grain size of $\sim 12 \mu \mathrm{m}$. The discontinuous flow is characterized by the appearance of a yield point phenomenon followed by a pronounced strain hardening to a large tensile strain.

3. The yield point phenomenon leads to an increase in the Hall-Petch slope from 140 $\mathrm{MPa} \cdot \mu \mathrm{m}^{0.5}$ at grain sizes larger than $12 \mu \mathrm{m}$, increasing with decreasing grain size to $188 \mathrm{MPa} \cdot \mu \mathrm{m}^{0.5}$ at a grain size of $3.3 \mu \mathrm{m}$. In particular, the yield point phenomenon leads to an enhancement in the strength $\sigma 0.2$ to $173 \mathrm{MPa}$ and an increase in total elongation to $36.6 \%$ at a grain size of $3.3 \mu \mathrm{m}$.

\section{Acknowledgements}

This work was sponsored by the State Key Research and Development Program of Ministry of Science and Technology (MOST) of China (2016YFB0700400), National Natural Science Foundation of China (Nos. 51471039, 51421001), Fundamental Research Fund of Central Universities of China (No. 2018CDJDCL0019) and the European Research Council (ERC) under the European Union's Horizon 2020 research and innovation programme (No. 788567). NH thanks the support of the 111 Project (B16007) by the Ministry of Education and the State Administration of Foreign Experts Affairs, China. Valuable discussions with Prof. A. Godfrey (Tsinghua University) are greatly acknowledged.

\section{References}

[1] I. Polmear, D. StJohn, J.F. Nie, M. Qian, Light alloys: metallurgy of the light metals, Butterworth-Heinemann, 2017.

[2] B.L. Mordike, T. Ebert, Magnesium: Properties-applications-potential, Mater. Sci. Eng. A 302 (2001) 37-45.

[3] T.C. Chang, J.Y. Wang, O. Chia-Ming, S. Lee, Grain refining of magnesium alloy AZ31 by rolling, J. Mater. Process. Tech. 140 (2003) 588-591.

[4] X. Luo, T.L. Huang, Y.H. Wang, Y.C. Xin, G.L. Wu, Strong and ductile AZ31 Mg 
alloy with a layered bimodal structure, Sci. Rep. 9 (2019) 5428.

[5] W.J. Kim, S.I. Hong, Y.S. Kim, S.H. Min, H.T. Jeong, J.D. Lee, Texture development and its effect on mechanical properties of an AZ61 Mg alloy fabricated by equal channel angular pressing, Acta Mater. 51 (2003) 3293-3307.

[6] J. Koike, T. Kobayashi, T. Mukai, H. Watanabe, M. Suzuki, K. Maruyama, K. Higashi, The activity of non-basal slip systems and dynamic recovery at room temperature in fine-grained AZ31B magnesium alloys, Acta Mater. 51 (2003) 20552065.

[7] K. Edalati, A. Yamamoto, Z. Horita, T. Ishihara, High-pressure torsion of pure magnesium: evolution of mechanical properties, microstructures and hydrogen storage capacity with equivalent strain, Scripta Mater. 64 (2011) 880-883.

[8] M. Kai, Z. Horita, T.G. Langdon, Developing grain refinement and superplasticity in a magnesium alloy processed by high-pressure torsion, Mater. Sci. Eng. A 488 (2008) 117-124.

[9] S. Sandlobes, S. Zaefferer, I. Schestakow, S. Yi, R. Gonzalez-Martinez, On the role of non-basal deformation mechanisms for the ductility of $\mathrm{Mg}$ and $\mathrm{Mg}-\mathrm{Y}$ alloys, Acta Mater. 59 (2011) 429-439.

[10] J.P. Hadorn, T.T. Sasaki, T. Nakata, T. Ohkubo, S. Kamado, K. Hono, Solute clustering and grain boundary segregation in extruded dilute Mg-Gd alloys, Scripta Mater. 93 (2014) 28-31.

[11] M. Bugnet, A. Kula, M. Niewczas, G.A. Botton, Segregation and clustering of solutes at grain boundaries in Mg-rare earth solid solutions, Acta Mater. 79 (2014) 6673.

[12] H. Fan, S. Aubry, A. Arsenlis, J.A. El-Awady, Grain size effects on dislocation and twinning mediated plasticity in magnesium, Scripta Mater. 112 (2016) 50-53.

[13] M.R. Barnett, Z. Keshavarz, A.G. Beer, D. Atwell, Influence of grain size on the compressive deformation of wrought Mg-3A-1Zn, Acta Mater. 52 (2004) 5093-5103.

[14] S.R. Agnew, M.H. Yoo, C.N. Tome. Application of texture simulation to understanding mechanical behavior of $\mathrm{Mg}$ and solid solution alloys containing Li or Y, Acta Mater. 49 (2001) 4277-4289.

[15] V. Herrera-Solaz, P. Hidalgo-Manrique, M.T. Pérez-Prado, D. Letzig, J. Llorca, J. Segurado, Effect of rare earth additions on the critical resolved shear stresses of magnesium alloys, Mater. Lett. 128 (2014) 199-203. 
[16] P.D. Wu, X.Q. Guo, H. Qiao, S.R. Agnew, D.J. Lloyd, J.D. Embury, On the rapid hardening and exhaustion of twinning in magnesium alloy, Acta Mater. 122 (2017) 369377.

[17] D. Buey, L.G. Hector Jr, M. Ghazisaeidi, Core structure and solute strengthening of second-order pyramidal $<\mathrm{c}+\mathrm{a}>$ dislocations in Mg-Y alloys, Acta Mater. 147 (2018) $1-9$.

[18] Z. Ding, W. Liu, H. Sun, S. Li, D. Zhang, Y. Zhao, E.J. Lavernia, Y. Zhu, Origins and dissociation of pyramidal $<\mathrm{c}+\mathrm{a}>$ dislocations in magnesium and its alloys, Acta Mater. 146 (2018) 265-272.

[19] R. Ahmad, B. Yin, Z. Wu, W.A. Curtin, Designing high ductility in magnesium alloys, Acta Mater. 172 (2019) 161-184.

[20] A. Tehranchi, B. Yin, W.A. Curtin, Solute strengthening of basal slip in Mg alloys, Acta Mater. 151 (2018) 56-66.

[21] Y. Bu, Z. Li, J. Liu, H. Wang, D. Raabe, W. Yang, Nonbasal Slip Systems Enable a Strong and Ductile Hexagonal-Close-Packed High-Entropy Phase, Phys. Rev. let. 122 (2019) 075502.

[22] Z. Wu, R. Ahmad, B. Yin, S. Sandlöbes, W.A. Curtin, Mechanistic origin and prediction of enhanced ductility in magnesium alloys, Science. 359 (2018) 447-452.

[23] R. Zheng, T. Bhattacharjee, A. Shibata, T. Sasaki, K. Hono, M. Joshi, N. Tsuji, Simultaneously enhanced strength and ductility of $\mathrm{Mg}-\mathrm{Zn}-\mathrm{Zr}-\mathrm{Ca}$ alloy with fully recrystallized ultrafine grained structures, Scripta Mater. 131 (2017) 1-5.

[24] B.C. Suh, M.S. Shim, K.S. Shin, N.J. Kim, Current issues in magnesium sheet alloys: where do we go from here, Scripta Mater. 84 (2014) 1-6.

[25] S.L. Couling, Yield points in a dilute magnesium-thorium alloy, Acta Metall. 7 (1959).

[26] N. Stanford, D. Atwell, M.R. Barnett, The effect of Gd on the recrystallisation, texture and deformation behaviour of magnesium-based alloys, Acta Mater. 58 (2010) 6773-6783.

[27] H. Somekawa, A. Singh, T. Mukai, T. Inoue, Effect of alloying elements on room temperature tensile ductility in magnesium alloys, Philos. Mag. 96 (2016) 2671-2685. [28] J. Wang, M.R.G. Ferdowsi, S.R. Kada, C.R. Hutchinson, M.R. Barnett, Influence of precipitation on yield elongation in Mg-Zn alloys, Scripta Mater. 160 (2019) 5-8. [29] T. Obara, H. Yoshinga, S. Morozumi, $\{1122\}<1123>$ Slip system in magnesium, 
Acta Metall. 21 (1973) 845-853.

[30] C.M. Cepeda-Jiménez, J.M. Molina-Aldareguia, M.T. Pérez-Prado, Effect of grain size on slip activity in pure magnesium polycrystals, Acta Mater. 84 (2015) 443-456.

[31] S. Sandlöbes, M. Friák, J. Neugebauer, D. Raabe, Basal and non-basal dislocation slip in Mg-Y, Mater. Sci. Eng. A 576 (2013) 61-68.

[32] M.H. Yoo, S.R. Agnew, J.R. Morris, K.M. Ho, Non-basal slip systems in HCP metals and alloys: source mechanisms, Mater. Sci. Eng. A 319 (2001) 87-92.

[33] M.H. Yoo, J.R. Morris, K.M. Ho, S.R. Agnew, Nonbasal deformation modes of HCP metals and alloys: role of dislocation source and mobility, Metall. Mater. Trans. A 33 (2002) 813-822.

[34] J. Jain, P. Cizek, K. Hariharan, Transmission electron microscopy investigation on dislocation bands in pure Mg, Scripta Mater. 130 (2017) 133-137.

[35] B.Y. Liu, F. Liu, N. Yang, X.B. Zhai, L. Zhang, Y. Yang, B. Li, J. Li, E. Ma, J.F. Nie, Z.W. Shan, Large plasticity in magnesium mediated by pyramidal dislocations, Science, 365(6448) (2019) 73-75.

[36] Y. Saito, H. Utsunomiya, N. Tsuji, Novel ultra-high straining process for bulk materials development of the accumulative roll-bonding (ARB) process, Acta Mater. 47 (1999) 579-583.

[37] X. Luo, Z.Q Feng, T.B. Yu, T.L. Huang, G.L Wu, N. Hansen, X.X. Huang, Dislocation and twinning based plasticity in $\mathrm{Mg}-3 \mathrm{Gd}$ deformed by accumulative rollbonding, Submitted for publication.

[38] H. Hu, Effect of solutes on Lüders strain in low-carbon sheet steels, Metall. Trans. A 14(1) (1983) 85-91.

[39] F.E. Hauser, P.R. Landon, J.E Dron, Deformation and fracture mechanisms of polycrystalline magnesium at low temperatures, ASM. 3 (1955) 73

[40] H. Yu, Y. Xin, M. Wang, Q. Liu, Hall-Petch relationship in Mg alloys: A review, J. Mater. Sci. Technol. 34 (2018) 248-256.

[41] W. Yuan, S.K. Panigrahi, J.Q. Su, R.S. Mishra, Influence of grain size and texture on Hall-Petch relationship for a magnesium alloy, Scripta Mater. 65 (2011) 994-997.

[42] H. Somekawa, T. Mukai, Hall-Petch relation for deformation twinning in solid solution magnesium alloys, Mater. Sci. Eng. A 561 (2013) 378-385.

[43] Y. Wang, H. Choo, Influence of texture on Hall-Petch relationships in an Mg alloy, Acta Mater. 81 (2014) 83-97. 
[44] X. Huang, N. Kamikawa, N. Hansen, Strengthening mechanisms and optimization of structure and properties in a nanostructured IF steel, J. Mater. Sci. 45 (2010) 47614769.

[45] S. Gao, M. Chen, S. Chen, N. Kamikawa, A. Shibata, N. Tsuji, Yielding behavior and its effect on uniform elongation of fine grained IF steel, Mater. Trans. 55 (2014) 73-77.

[46] D.J. Lloyd, L.R. Morris, Lüders band deformation in a fine grained aluminium alloy, Acta Mater. 25 (1977) 857-861.

[47] N. Kamikawa, X. Huang, N. Tsuji, N. Hansen, Strengthening mechanisms in nanostructured high-purity aluminium deformed to high strain and annealed, Acta Mater. 57 (2009) 4198-4208.

[48] G.M. Le, A. Godfrey, N. Hansen, Structure and strength of aluminium with submicrometer/micrometer grain size prepared by spark plasma sintering, Mater. Design 49 (2013) 360-367.

[49] K.N. Zhu, A. Godfrey, N. Hansen, X.D. Zhang, Microstructure and mechanical strength of near- and sub-micrometre grain size copper prepared by spark plasma sintering, Mater. Design 117 (2017) 95-103.

[50] X. Huang, N. Hansen, N. Tsuji, Hardening by annealing and softening by deformation in nanostructured metals, Science. 312 (2006) 249-251.

[51] M.A. Meyers, O. Vöhringer, V.A. Lubarda, The onset of twinning in metals: a constitutive description, Acta mater. 49 (2001) 4025-4039.

[52] C.M. Cepeda-Jiménez, J.M. Molina-Aldareguia, M.T. Pérez-Prado, Origin of the twinning to slip transition with grain size refinement, with decreasing strain rate and with increasing temperature in magnesium, Acta Mater. 88 (2015) 232-244.

[53] M.R. Barnett, A rationale for the strong dependence of mechanical twinning on grain size, Scripta Mater. 59 (2008) 696-698.

[54] J.D. Eshelby, F.C. Frank, F.R.N. Nabarro, The equilibrium of linear arrays of dislocations, Philos. Mag. 42 (1951) 351-364.

[55] E.O. Hall, The deformation and ageing of mild steel: III discussion of results, Proceedings of the Physical Society. Section B. 64(1951) 747.

[56] N.J. Petch, The Cleavage Strength of Polycrystals, J. Iron. Steel. Inst. 174 (1953) $25-28$.

[57] S.R. Agnew, Ö. Duygulu, Plastic anisotropy and the role of non-basal slip in 
magnesium alloy AZ31B, Int. J. Plasticity. 21 (2005) 1161-1193.

[58] S.R. Agnew, J.A. Horton, M.H. Yoo, Transmission electron microscopy investigation of $<\mathrm{c}+\mathrm{a}>$ dislocations in $\mathrm{Mg}$ and $\alpha$-solid solution $\mathrm{Mg}$-Li alloys, Metall. Mater. Trans. A 33(2002) 851-858.

[59] S. Sandlöbes, Z. Pei, M. Friák, L.F. Zhu, F. Wang, S. Zaefferer, D. Rabbe, J. Neugebauer, Ductility improvement of $\mathrm{Mg}$ alloys by solid solution: Ab initio modeling, synthesis and mechanical properties, Acta Mater. 70 (2014) 92-104. 